\title{
La Economía del Bien Común en el ámbito local
}

\author{
Rosario Gómez-Álvarez Díaz \\ Rafael Morales Sánchez \\ Carmen Rodríguez Morilla
}

RESUMEN: Este trabajo presenta la Economía del Bien Común en el ámbito municipal. Para ello se describe qué es un Municipio del Bien Común y las cinco estrategias propuestas para alcanzarlo: creación de asambleas democráticas, aplicación del Balance del Bien Común Municipal, promoción de la Economía del Bien Común en las organizaciones, creación del Índice del Bien Común Municipal y participación en la creación de una Región del Bien Común. El modelo tiene una vocación de transformación real de todo el sistema económico, fundamentando su construcción en la democracia y a partir de una red desde el ámbito local. La Economía del Bien Común trata de crear los incentivos para que la actividad económica esté orientada hacia el Bien Común, entendido como la promoción de los valores humanos de la dignidad humana, solidaridad, sostenibilidad, justicia social y la democracia y transparencia. Para lograrlo plantea su medición mediante el balance del bien común y las modificaciones legales para que las empresas, y otras organizaciones cooperen para la generación de bien común, en lugar de competir por la maximización del beneficio. Por ello, este trabajo sostiene que la Economía del Bien Común concebida a escala municipal, proporciona un marco completo y coherente de análisis desde donde abordar el desarrollo local. La presentación del marco teórico de la Economía del Bien Común en el ámbito municipal pretende crear un aporte de síntesis útil a profesionales de la investigación y los profesionales del ámbito municipal.

PALABRAS CLAVE: Economía del Bien Común, desarrollo local, participación ciudadana, gestión pública, índice municipal del bien común, balance del bien común municipal, empresas sociales.

CLAVES ECONLIT: A13, D63, O35, P1, P4, R11.

Cómo citar este artículo / How to cite this article: GÓMEZ-ÁLVAREZ, R., MORALES, R. \& RODRÍGUEZ, C. (2017): "La Economía del Bien Común en el ámbito local", CIRIEC-España, Revista de Economía Pública, Social y Cooperativa, 90, 189-222.

Correspondencia: Rosario Gómez-Álvarez Díaz, dpto. Economía e Historia Económica, Universidad de Sevilla, proferora Contratada-doctor, charogomez@us.es; Rafael Morales Sánchez, dpto. Organización de Empresa y Marketing, Universidad Pablo de Olavide, profesor Contratado-doctor, rmorsan@upo.es; Carmen Rodríguez Morilla, dpto. Economía Aplicada II, Universidad de Sevilla, profesora Colaboradora, cmorilla@us.es. 


\section{EXPANDED ABSTRACT}

\section{The Economy for the Common Good at a Local Level}

This paper aims to generate debate among researchers and people involved in the practice of municipal government regarding the applicability and real possibilities to implement the municipal version of the Economy for the Common Good (ECG) model.

This underlying aim has resulted in two fundamental objectives. Firstly, to describe how the Economy for the Common Good adapts its theoretical framework to the local level and to present the five strategies proposed by the ECG to become a Common Good Municipality (CGM). Secondly, to reflect on the possible development of these strategies at a practical level.

To achieve these objectives, this paper briefly presents the theoretical model of the ECG. It then goes on to set out the five strategies proposed to implement the ECG at a local or municipal level: 1) establish a Local Economic Convention; 2) implement a Common Good Balance Sheet for local authority administration and economics departments, and for public corporations and organizations; 3 ) Promote Common Good Companies; 4) Introduce a Local Common Good Index; and 5) Create a Common Good Region. This article focuses particularly on describing the indicators used by the Common Good Balance Sheet and the extent to which they are related to other existing indicators.

The methodology used is descriptive: having compiled and reviewed the existing bibliography, a series of qualitative interviews were conducted with members of the Association for the Promotion of ECG. The research identifies the main sources to determine the conceptual framework, indicating the origin, definitions and component elements thereof. Existing specific legislation was also reviewed, in particular pertaining to the EU, but also national legislation. Similarly, reports from eminent public and private organizations were consulted, along with best practice and good governance guidelines, especially in the public sector.

The Economy for the Common Good aims to create incentives to steer economic activity toward the common good. This common good refers to the promotion of human values such as human dignity, solidarity, sustainability, social justice, democracy and transparency. To achieve this objective, it proposes to assess the common good through the Common Good Balance Sheet and to modify legal norms so that companies and other organizations can cooperate for the common good rather than compete for maximization of profits. 
At a municipal level, the proposal of the ECG aims to foster an understanding of politics as an instrument that increases the common good of all and which contributes to enriching those values that the ECG considers positive and favorable to quality of life. The ECG offers an alternative theoretical discourse to the maximization of production and competition and, above all, it offers a practical tool to bring about change over to this new way of thinking. The model strives to effect real transformation in the entire economic system, basing its construction on democracy and starting with local networks.

This model challenges citizens to reflect on the basic values for leading a shared good life in common. This approach is based on the idea that people can dialogue and build common spaces, creating common interests, not just 'exchanging' individual interests. These common interests can be sought in human values, the five values proposed by the ECG as a starting point to build a 'constitutional' framework of coexistence.

Another key contribution made by the economic and social model of the ECG is the index proposed to measure the common good. It is a metric of what people want in terms of coexistence, since the Local Common Good Index can serve as a true compass for evaluating local policies. In addition, the Common Good Balance Sheet offers a new public management tool. Both the Local Common Good Index and the Common Good Balance Sheet for local authority administration and economics departments, and for public corporations and organizations, are thus shown to be effective tools of real transformation.

Regarding this measure of the impact of public activity, there are four differentiating elements between the proposals set out to measure the economic, social and environmental impact of public administration activities (and specifically in the municipal area) and the proposal of the Economy for the Common Good. The first differentiating element is the object of evaluation: the common good. Although the ECG shares with public social responsibility the basic principles of participation, transparency and sustainability, in the ECG model, this common good articulates and gives prominence to the values of dignity (in a broad sense and not only restricted to the field of labor relations), social justice and solidarity, elements that do not have the same relevance in the other evaluations, or are not even present.

The second differentiating element is the methodology used to define the local common good, since, in the paradigm of the Economy for the Common Good, the construction of that common good is a nonaprioristic participatory process and can vary from one territory to another. Therefore, under no circumstances is the common good considered an objective determined by the local public administration, but rather an objective chosen and defined by the members of the municipality.

The third differentiating element is that public social responsibility enters into an arbitrary logic. That is, this public social responsibility appears as an 'added value' to compliance with legal norms. However, the reflection of the ECG is that any organization, including public administration, has to consider how 
it aims to contribute to the common good as an organization, and therefore that contribution becomes the fundamental organizational motivation.

Finally, the last element differentiating the proposals of public administration social responsibility and ECG proposal rests on the idea of development based on competitiveness, an enduring notion in approaches to public administration social responsibility. Faced with this idea of competition for the acquisition and use of resources, ECG argues that the driving force of society is cooperation.

The ECG proposal does not advocate a larger public sector, but instead 'another public sector'. A public administration that gives way to civil society, through greater democratic participation and the facilitation of spaces for the development of collective projects. This public administration also has other basic tools such as regulations, public spending and taxation to create incentives that favor the promotion of the common good.

The proposal presented here requires further and more in-depth development in certain aspects: forms of democratic participation, participatory construction of the index, modification of public management culture, citizen awareness, creation of business and social networks based on cooperation and not competition, etc. In this task, the ECG can be supported by a wide variety of other theoretical and practical proposals in the field of economics: social and solidarity economy, circular economy, collaborative economy, economy of the commons, economics of care, ecofeminism, etc.; and of politics: participatory budgets, liquid democracy, etc. In addition, this task needs and connects with law, anthropology, education, sociology, etc. The ECG is presented in its nature as a holistic model, because it asks how a person can live better within society, and the answer, therefore, must be sought in all fields of knowledge.

The research outlined here aims to generate a framework for analysis, debate and discussion around the elaboration of effective development strategies at a municipal level. For this reason, the main contribution of this research is to synthesize for the first time information related to the application of the ECG model at a municipal level. In addition, in this process of synthesis, it reflects on the theoretical foundations of the strategies and on the relations established with other theoretical models of local development or social economy. The novelty of the ECG applied to the municipal sphere is based on its theoretical and practical contribution to the definition of a common good for the municipality, its measurement and the strategies to promote it.

This work has presented for the first time the Economy for the Common Good applied at a municipal level, detailing the strategies a municipality must follow to become a Common Good Municipality. This presentation has described the indicators used by the Common Good Balance Sheet. This is a new evaluation tool for its object of evaluation, the common good, for its subject, public administration, and for its vocation of transforming society. Future research might compare the indicators of the Municipal/Local Common Good Balance Sheet to others that are already being used at a municipal 
level to try to improve these indicators and reflect on their suitability. Therefore, this work is presented as an initial contribution to reflection and debate regarding the proposal of the Common Good Economy in relation to other critical contributions that consider the social, economic and environmental dimensions of the municipality. It is also hoped that this article will provide a working document so that the scientific community from diverse and specific fields of knowledge and, above all, companies, social entities and public bodies can contribute to the creation of a social and economic space that truly promotes the Common good from the municipal level for all citizens.

KEYWORDS: Economy for the common good, local development, local common good index, local common good balance sheet, social enterprises.

\section{1.- Introducción}

La mayoría de teorías del desarrollo a lo largo del siglo XX han puesto el acento en el crecimiento económico como objetivo primordial (Hirschman, 1980). Dentro de estas teorías aparece el término desarrollo local como modelo de planificación microeconómica para que mediante el aprovechamiento de los recursos endógenos del territorio se genere empleo, renta y riqueza y con ello el aumento del bienestar social y la calidad de vida. Como consecuencia, el paradigma que subyace es el del crecimiento del PIB como objetivo y la competitividad como herramienta (Hidalgo-Capitán, 2011).

Frente a este paradigma, han aparecido con posterioridad nuevas propuestas que sitúan a las personas como elemento fundamental del desarrollo, donde el PIB es sólo un medio: teoría de las capacidades de Amartya Sen (1999), economía social y solidaria (Coraggio,1998), teoría del decrecimiento (Latouche, 2007), economía del buen vivir (Acosta y Martínez, 2009), ecofeminismo (Herrero, 2012), economía circular (Braungart y Mcdonough, 2005), economía colaborativa (Cañigueral, 2014), entre otras. En ellas aparece también la reivindicación del espacio local, como marco natural para la implantación de sus propuestas y la importancia del empoderamiento de la población.

Más recientemente, la Economía del Bien Común (EBC) (Felber, 2012) ofrece un nuevo modelo económico, social y político basado en los valores esenciales de la dignidad humana, la solidaridad, la sostenibilidad ecológica, la justicia social y la democracia. La EBC no es un modelo cerrado, plantea un modelo en construcción mediante la herramienta básica de la democracia, la participación y el diálogo. Fiel a esta propuesta metodológica, la EBC posibilita la implantación de su modelo en y desde el ámbito local, con un claro protagonismo de la sociedad civil para construir otra economía. 
En este trabajo sostenemos que la EBC concebida a escala municipal, proporciona un marco completo y coherente de análisis desde donde abordar el desarrollo local. Por tanto, este artículo tiene dos objetivos fundamentales: en primer lugar presentar cómo la Economía del Bien Común adapta su marco teórico al ámbito local y describir las cinco estrategias propuestas por la propia EBC para conseguir ser un Municipio del Bien Común (MBC); y en segundo lugar, reflexionar sobre el posible desarrollo de estas estrategias a nivel práctico.

La metodología empleada es de carácter descriptiva. Se parte de la recopilación de la bibliografía existente, y de la realización de entrevistas cualitativas con personas pertenecientes a la Asociación para el Fomento del Bien Común para la determinación del marco conceptual, señalando el origen, las definiciones y los elementos que lo conforman ${ }^{1}$. También se considera la normativa específica existente, en especial la UE, y en segundo lugar, la normativa propia del legislador nacional. De igual forma se revisan informes de organismos públicos y privados de reconocido prestigio, y guías de buenas prácticas o de buen gobierno, en especial en el sector público.

A partir de esta información, realizamos una exposición crítica del modelo de la EBC aplicada al ámbito municipal con un doble propósito. Con este trabajo se pretende contribuir a la difusión de esta propuesta en el ámbito académico. Asimismo esperamos generar un marco para el análisis, el debate y la discusión en torno al desarrollo de estrategias efectivas de desarrollo en el ámbito municipal desde la EBC, para poder plantear mejoras futuras en las políticas públicas locales reales.

La aportación fundamental de este trabajo consiste en sintetizar por primera vez la información referida a la aplicación de la EBC al ámbito municipal. En este proceso de síntesis, además, se reflexiona en los fundamentos teóricos de las estrategias y en las relaciones con los otros modelos teóricos del desarrollo local o de la economía social. La novedad que supone la EBC aplicada al ámbito municipal se basa en su contribución teórica y práctica a la definición de un bien común del municipio, su medición y las estrategias para impulsarlo.

Para conseguir estos objetivos, nuestro trabajo se organiza en torno a la siguiente estructura: en primer lugar se presenta brevemente el modelo teórico de la EBC. A continuación se desarrollan aquellas aportaciones que afectan específicamente al ámbito municipal y se presenta el Municipio del Bien Común. En el siguiente apartado se desarrollan las cinco estrategias propuestas para implantar la EBC a nivel municipal. Especial importancia tiene la descripción de los indicadores que utiliza la Matriz del Bien Común Municipal y en qué medida se relacionan con otros indicadores existentes. El artículo termina con algunas reflexiones en torno a las posibilidades teóricas y sobre todo prácticas que ofrece el modelo de la EBC a nivel local. 


\section{2.- Marco teórico}

El libro "la Economía del Bien Común" (Felber, 2012) es el fruto del proceso de reflexión realizado por su autor Christian Felber, profesor de Economía y activista austriaco, junto a un grupo de empresarios, en 2010. De hecho, la EBC es también una red de activistas, que se ha extendido por más de 20 países, entre ellos Alemania, Italia, Suiza, Inglaterra o Chile. En España aparecieron los primeros grupos impulsores a nivel local (Campos de Energía) en el año 2012, formados por grupos de personas, empresas y comunidades que profundizan, extienden y desarrollan el concepto de la Economía del Bien Común, generando redes de cooperación desde lo local hacia lo global. Posteriormente se constituyó la Asociación Federal Española para el Fomento de la Economía del Bien Común, y las asociaciones de Euskadi, Cataluña, Valencia, Canarias y Andalucía. Asimismo, en 2015 se produjo un hito importante de cara a la extensión de la EBC a nivel europeo. El Comité Económico y Social Europeo aprobó un dictamen en el que se recoge que "el modelo de la Economía del Bien Común (EBC) está concebido para incluirse en el marco jurídico europeo y nacional con el fin de avanzar hacia un mercado único europeo a través de una economía más ética basada en los valores europeos y los logros de las políticas de responsabilidad social, creando además sinergias encaminadas a su reforzamiento" (Comité Económico y Social Europeo, 2016).

Centrándonos en los pilares teóricos de la EBC, podemos destacar tres supuestos: el bien común como objetivo de la economía, la cooperación como base de las relaciones económicas y la democracia como pilar legitimador de cualquier sistema social.

En primer lugar, la meta de cualquier sociedad es el bien común y no el mero crecimiento económico y la acumulación de capital, que son medios pero no fines sociales, tal como se recoge en muchas constituciones. Este concepto ha disfrutado de una larga tradición en filosofía y política, y en los ordenamientos jurídicos (Argandoña, 2011; Gómez y Gómez-Álvarez, 2016) como concepto rector de la vida social. A pesar de la dificultad para su concreción, Felber entiende que el bien común se fundamenta en el respeto y fomento de los valores humanos que compartimos, y que tienen su plasmación en los derechos humanos. Por ello la EBC propone una economía basada en valores similares a los que fortalecen las relaciones humanas (Felber, 2012): dignidad humana, solidaridad, sostenibilidad ecológica, justicia social, participación democrática y transparencia.

Así, una determinada actividad humana aportará al bien común en la medida que favorezca el desarrollo de estos valores. En el ámbito macroeconómico de un país el éxito se debería medir por el Producto del Bien común, propuesta todavía sin desarrollar, y a nivel microeconómico por el Balance del Bien Común, herramienta diseñada para el ámbito de la empresa y que puede extrapolarse a otras organizaciones, incluida la administración pública y por tanto el ayuntamiento. 
Este balance está configurado por una serie de indicadores que miden cómo la empresa fomenta dichos valores cuando se relaciona con: proveedores, financiadores, empleados/propietarios, clientes/productos/servicios/co-empresas, y ámbito social: región, generaciones futuras, personas y naturaleza. La intersección de criterios, valores y grupos, genera 17 indicadores.

Cada empresa puede evaluar cuantitativamente cuál es su contribución al bien común para cada uno de los indicadores, siendo 1.000 puntos la evaluación máxima total que puede obtener una empresa. El informe que recoge toda la información detallada se denomina Balance, y el resumen de dicha evaluación mediante una única tabla se denomina Matriz del Bien Común.

\section{Figura 1. La Matriz del Bien Común 4.1}

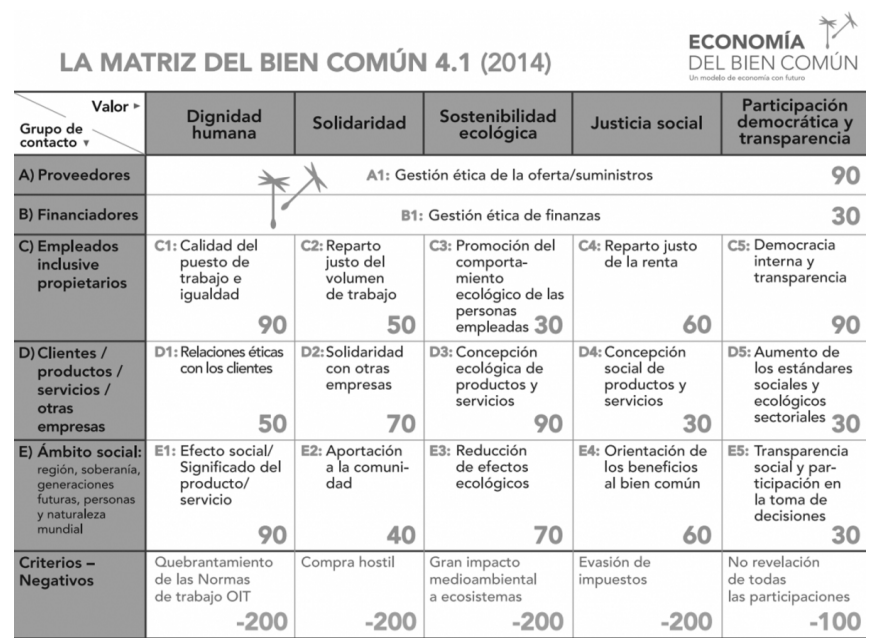

FUENTE: Disponible en http://economia-del-bien-comun.org.

En otro orden de cosas, en el sistema predominante actual se incentiva la competitividad, que se ha demostrado incapaz de conseguir una calidad de vida digna para todos los ciudadanos, a pesar de ser considerado como un sistema natural (Hayek,1986). Esta competitividad promueve el afán de acumulación, que está poniendo en riesgo la sostenibilidad de nuestro planeta. Sin embargo, el mercado es una institución social, no un proceso natural, y como consecuencia puede ser diseñado desde la democracia y orientada al bien común, mediante normas e incentivos, que fomenten la cooperación, siendo este el segundo pilar de este modelo (Felber, 2012; Polanyi, 2001; North, 1990).

Felber plantea una guía de ruta. En una primera etapa, la EBC propone que empresas, municipios y organizaciones se comprometan a medir su aporte al bien común mediante el balance. En una segunda etapa, se prevé que las empresas/organizaciones que ya hayan medido su participación al bien común, hagan público sus resultados mediante su publicación en los medios de comunicación, 
en la página web de la EBC y otras fórmulas de comunicación. En esta etapa, las empresas etiquetarán sus productos con un distintivo o color en función de la puntuación obtenida. De esta manera las personas cuando consumen serán conocedores de cómo la empresa favorece al bien común para poder ejercer su derecho de participación y su responsabilidad individual y colectiva en las compras que realiza. En una tercera etapa, las empresas con mejores balances deberían contar con incentivos fiscales, discriminación positiva en los procesos de contratación pública, cooperación con la investigación universitaria... de forma que la sociedad premie a las empresas que están generando bien común, frente a aquellas que no lo hacen (Felber, 2012).

El tercer supuesto es que la construcción democrática es el elemento legitimador de otro modelo económico (Felber, 2012:61). Para ello se requiere el desarrollo de una conciencia soberana, reivindicando que la soberanía está en el pueblo. La potestad básica del "soberano" es la reforma de la ley, y por tanto el ejercicio de ésta se debería poder concretar en la posibilidad de que el pueblo pudiera (Felber, 2012:166): "elegir un gobierno concreto, revocar al gobierno, corregir al parlamento en un anteproyecto de ley, él mismo proponer leyes a votación, modificación de la Constitución por iniciativa propia, votar directamente en una asamblea constitucional y controlar y dirigir los servicios públicos básicos más importantes". Esta potestad se debería poder ejercer mediante la democracia directa, inspirada en el modelo suizo.

Es de especial relevancia la propuesta de la redacción de la constitución, y su posterior aprobación, mediante mecanismos de democracia directa, como en el caso de Zurich o Islandia (Felber, 2012:180). Con tal fin propone la creación de asambleas constituyentes, que denomina convenciones, para que mediante la democracia directa, el pueblo apruebe las normas constitucionales para la economía, la educación, los servicios de interés general, estando dentro de estos los denominados bienes comunales democráticos, medios de comunicación, y el propio diseño del sistema democrático.

Por ello reivindica y argumenta de forma extensa la importancia de la democracia directa, pero considera que esta debe convivir con la democracia representativa y la democracia participativa. La democracia representativa es necesaria en la medida en la que se agiliza la toma de decisiones, pero el parlamento y el gobierno nunca pueden ser más importantes que el propio pueblo soberano.

En nuestra opinión, detrás de esta propuesta está la reivindicación de la política como fuerza reguladora y transformadora de la sociedad (Bauman, 2001), ya que: "La política existe porque necesitamos -a pesar de las diferencias- vivir juntos. Pero la política no es únicamente la forma de resolver nuestros conflictos presentes, sino también el medio para dar forma a nuestro futuro. La política es pues un ingrediente fundamental para la convivencia, pero para poder actuar requiere de una espacio público en el que poder encontrarnos, debatir y tomar decisiones vinculantes para la colectividad" (Bruqué, 2009:126).

Sin embargo, en un mundo individualizado, cada uno diseña su biografía, no construye el futuro de todos, no pretende incidir en la el entorno, solo adaptarse, y la política se entiende, como defiende 
Nozick (1974), como un mecanismo para vivir juntos, pero en proyectos separados. Frente a esta visión, existe una visión antropológica del hombre que reconoce en éste su potencial para la colaboración, la solidaridad y el compromiso colectivo. Bajo ese paradigma, la política no es un mal necesario, sino un entramado ético donde se conforman asociaciones y proyectos comunes. La forma de organizar ese espacio político es la democracia, pero no como una mera consulta cada cuatro años. Por el contrario, el ciudadano reivindica ser partícipe en las decisiones que les afecta: es la denominada "democracia radical" (Cortina, 1993).

En la EBC, hay por tanto, una defensa de la persona como ciudadana y del sometimiento de la organización económica, como institución y no como orden natural, a las decisiones políticas. En definitiva, La EBC invita a pensar como la economía puede servir a los intereses de todos, por ese motivo no es una teoría cerrada ni excluyente, porque su base metodológica se fundamenta en el diálogo y en la democracia, como mecanismos de construcción social.

\section{3.- La Economía del Bien Común a nivel municipal}

En la actualidad existe un cierto consenso en considerar la dimensión local como el hábitat natural donde germinan con mayor éxito los procesos de desarrollo (Bustelo, 1998; Unceta, 2009). Sin embargo, no fue hasta los ochenta cuando se comenzaron a plasmar desde el plano institucional, políticas de desarrollo que suponían una alternativa a las políticas macroeconómicas globales alejadas de las realidades locales. Sin duda, la puesta en marcha del Programa de las Naciones Unidas para el Desarrollo (PNUD) marcó la inflexión definitiva de esta tendencia a nivel mundial estableciendo dos principios esenciales. El primero, pensar en lo global y actuar localmente y el segundo, la participación de las comunidades locales en los planes de desarrollo. Este esfuerzo por plantear un desarroIlo alternativo ha desembocado en múltiples propuestas, bien centradas en diferentes estrategias de desarrollo local en el sentido tradicional, o bien en redefinir el concepto de desarrollo pero desde lo local. ${ }^{2}$

En el caso de la EBC, los municipios constituyen el nivel de actuación política más cercano al ciudadano, y se presenta como el punto de partida adecuado para impulsar un proceso de transformación, basado en sus tres pilares básicos. En primer lugar el fin de la economía de un territorio, de un municipio, deja de ser el crecimiento para centrarse en conseguir el bien común de sus habitantes; en segundo lugar ese bien común es construido a través de la cooperación intramunicipio e intermunici-

2.- Abordar en profundidad las diferentes propuestas excede el objetivo de este trabajo. Para ver otras estrategias de desarrollo local se pude consultar Escobar (2005) y otros conceptos de desarrollo se muestran en Unceta (2009), Zurbano et. al (2014), Carpi (2008). 
pios; y en tercer lugar, dicho proceso deberá llevarse a cabo incorporando transversalmente la participación de los diferentes actores que integran un territorio en la articulación de todas sus políticas.

Más que una estrategia de desarrollo dirigida por las autoridades locales lo que la EBC propone es una metodología originada desde una reflexión colectiva y participativa donde cada una de las políticas que traten de incentivar el fomento del bien común está articulada en torno a valores ampliamente compartidos. La EBC no renuncia al fomento de la producción de bienes y servicios, en la medida en que son un medio, pero no son el fin en torno a la cual organizar la vida económica, social y política.

Entre los objetivos de este modelo está el fomentar un cambio en la cultura económica y política, por ello propone un modo de pensar y actuar desde lo local fundamentado en valores comunes como elemento en torno al cual comenzar a relacionarnos y organizarnos. La transición hacia un nuevo modelo se fundamenta en una estrategia de colaboración colectiva, basada en la participación democrática y el compromiso de las personas, con la involucración de las empresas y de otras organizaciones (ONGs, movimientos sociales, asociaciones y comunidades vecinales...) y, por supuesto, con el compromiso de los gobernantes. La EBC es un movimiento "de abajo hacia arriba" y, por esa razón, el lugar natural por donde tiene más sentido empezar a impulsarlo es en el municipio. A ello se debe unir los cambios legislativos necesarios para crear los incentivos para la cooperación. Estos son fundamentales como impulso de las buenas prácticas por parte de todas las personas y colectivos que interactúan dentro de un territorio, y que éste se convierta en un proceso al que se unan otros niveles territoriales mayores (Felber, 2012:227).

En concreto, desde el ámbito local podemos identificar dos niveles institucionales complementarios desde donde puede nacer la orientación hacia una economía del bien común:

- El municipio, entendido como el conjunto de personas y colectivos que integran un territorio

- El ayuntamiento, como organización que gestiona y promueve las diferentes políticas públicas a través de su gobierno.

Un Municipio del Bien Común tiene como meta garantizar que en las relaciones que se establecen entre todas las personas y organizaciones de su territorio estén presentes los valores de: la dignidad humana, la solidaridad, la sostenibilidad, la justicia social, la democracia participativa y la transparencia (Felber, 2012:225).

La dignidad humana, en términos de Kant (1989), afirma que el hombre es un fin en sí mismo, no un medio para usos de otros individuos. Se expresa así la autonomía y capacidad moral de las personas, constituyéndose en el fundamento indiscutible de los derechos humanos. Adaptándolo a la óptica del municipio, podemos exponer que las relaciones en el territorio se deben fundamentar en el reconocimiento de todos los ciudadanos como personas con dignidad propia, y tener en cuenta a todos y cada uno de ellos, favoreciendo las condiciones para que se cumplan los derechos humanos y asegurando los servicios básicos para que las personas puedan vivir dignamente. 
Razeto (2015), autor emblemático de la economía solidaria, define la solidaridad en el ámbito económico, como la relación de horizontalidad entre las personas que constituyen un grupo, y que pretende la ayuda mutua, de forma que es un vínculo duradero basado en un compromiso de trabajar mediante la cooperación. Desde la óptica del municipio, podemos exponer que se debe favorecer las relaciones entre los grupos sociales, económicos y políticos del municipio, fomentando lazos de unión y cooperación duraderos con éstos para poder llevar a cabo medidas de mejora del bienestar del municipio.

La sostenibilidad ecológica quedó definida en el Informe Brundtland (WCED, 1987) como el desarrollo que satisface las necesidades del presente sin comprometer la capacidad de las generaciones futuras para satisfacer sus propias necesidades. Somos seres ecodependientes y por tanto nuestra supervivencia está condicionada al cuidado y mantenimiento de nuestros recursos naturales. Esta es una labor común, donde el ayuntamiento, los ciudadanos, empresas y demás organizaciones del municipio representan un papel fundamental en lo que se refiere a la responsabilidad ecológica.

Las Naciones Unidas (2006) afirman que la justicia social "es un principio fundamental para la convivencia pacífica y próspera, dentro y entre las naciones. Defendemos los principios de justicia social cuando promovemos la igualdad de género o los derechos de los pueblos indígenas y de los migrantes. Promovemos la justicia social cuando eliminamos las barreras que enfrentan las personas por motivos de género, edad, raza, etnia, religión, cultura o discapacidad". La justicia social se refiere a las nociones fundamentales de igualdad de oportunidades, y de "derechos humanos" entendidos éstos más allá del concepto tradicional de justicia legal. Está basada en la equidad y en una distribución equitativa de la riqueza y es imprescindible para que los individuos puedan desarrollar su máximo potencial y para que se pueda instaurar una paz duradera. Desde el ámbito del municipio, la implementación de este valor puede llevarse a cabo tanto en funcionamiento interno del propio ayuntamiento como en el municipio, apostando por valores de igualdad y justicia y fomentando éstos entre la ciudadanía.

La participación ciudadana carece de una única definición pero en términos generales se reúnen bajo este término todas aquellas prácticas políticas y sociales a través de las cuales la ciudadanía pretende incidir sobre alguna dimensión de aquello que es público (Parés, 2009). Si atendemos al grado de intensidad de su ejercicio se puede emplear la escala de Arnstein (1969) que clasifica la participación en función de si esta consiste en información, comunicación, consulta, deliberación y decisión. En opinión de Parés (2009) las dos primeras formas establecen una relación unidireccional entre la administración y la ciudadanía y si bien son necesarias para una buena calidad democrática no generan capacidad de incidencia en la ciudadanía sobre la toma de decisiones públicas.

En cuanto a la transparencia, ésta se entiende como la información veraz que cualquier organización debería ofrecer al público, para mostrar su conducta. Su justificación reside en el hecho de que cualquier colectivo formal con personalidad jurídica, cuenta con una protección social que se legitima en función de su conducta y por tanto esta debe ser conocida por todos (Díaz, 2006). 
El ámbito municipal se presenta como el contexto adecuado para fomentar los valores de la participación democrática y la transparencia, por dos motivos. El primero de ellos es la cercanía entre el ciudadano y la administración, lo que reduce los costes de participación ciudadana (información, comunicación, consulta, deliberación y decisión); y el segundo es que una verdadera democracia solo se puede construir desde abajo.

La aplicación de la EBC en municipios se ha extendido en España de forma pionera ya que es aquí donde se empezó a adaptar el Balance del Bien común a la realidad local, en 2013. En la actualidad existe una red de municipios del bien común que comenzó de forma pionera con Muro de Alcoy, Miranda de Azán, Carcaboso, Orendain y el distrito de Horta-Guinardó en Barcelona a los que se han ido uniendo otros que simpatizan con el movimiento o que han aportado sus buenas prácticas en diferentes encuentros: Rubí, Santa Lucía de Tirajana, Eibar, Enguera, Torrelodones, Rivas Vaciamadrid, La Carolina, Alboraya, Barcelona, Vitoria-Gazteiz o Sevilla3.

\section{4.- Estrategias para orientar un municipio hacia el bien común}

En la obra de Felber (2012:225-227) se plantea una hoja de ruta basada en cinco estrategias específicas para que un municipio, que el autor denomina "comunidad", se convierta en un territorio que propicie el cambio de modelo de desarrollo y se convierta en un Municipio del Bien Común (MBC). Basándose en esa hoja de ruta, la Asociación Federal Española para el Fomento de la Economía del Bien Común (ASFEBC) aprobó el denominado "Protocolo del municipio del bien común" en el 2015. En ambas propuestas se recogen cinco estrategias, denominadas "semillas"4: la creación de Asambleas democráticas, la aplicación del Balance del Bien Común Municipal, la promoción de la EBC en organizaciones privadas, empresas, ONG, etc; la creación del Índice del Bien Común y la participación en la creación de una Región del Bien Común. liografía.

3.- Las referencias de los sitios web de los municipios afines a la Economía del Bien Común están recogidos en un apartado final de la bib-

4.- ASFEBC (2015): "Protocolo para declaración de municipios del bien común”, Documento aprobado en la Segunda Asamblea General de la Asociación Federal Española para el Fomento de la Economía del Bien Común, el 31/05/2015, documento interno de la ASFEBC, se puede solicitar a nodo-municipios@economia-del-bien-comun.es, pendiente de publicar en página web. 
A continuación analizamos todas estas estrategias, profundizando en diferentes aspectos que no se encuentran del todo definidos o formalizados en los dos documentos anteriormente mencionados 5 .

\subsection{Asamblea Democrática}

La primera estrategia para implementar la EBC que propone Felber (2012:226) es la realización de una convención económica municipal, insertada dentro de la lógica de la defensa de un sistema económico que debe ser diseñado y legitimado desde "abajo", desde "el pueblo soberano". En esta convención la ciudadanía fijaría unas veinte reglas jurídicas que deben regir la economía, en parte a nivel municipal, pero finalmente a nivel regional, nacional y a nivel europeo. Esta "convención económica municipal" podría convertirse en una iniciativa para constituir un grupo de presión a efectos de modificar la legislación nacional y europea, además de la local, y una estrategia de construcción constitucional de otro modelo económico. Por su parte, la ASFEBC, ha aprobado en su protocolo un concepto más amplio que el de "convención económica municipal" como es el de Asamblea democrática, que se concibe como una propuesta para mejorar la gestión y la participación democrática local.

Desde nuestro punto de vista, esta propuesta es más ambiciosa en la medida en la que se pretende crear una organización civil que genere una cultura de participación ciudadana y democrática, que abarque las diferentes cuestiones municipales. Ahora bien, uno de los elementos básicos de la participación ciudadana es la motivación, un objeto y un propósito, por tanto, es importante que en su implementación se determine claramente cuáles son éstos. Dentro de las diferentes opciones, la convención económica municipal podría ser un objetivo concreto para debatir en la asamblea.

Esta propuesta encuentra su fundamentación teórica más elaborada en la reivindicación de una sociedad civil activa en todos las relaciones políticas, económicas y sociales frente a la dualidad del mercado-estado (Oteo, 2005). Según Cortina (1993) la realización de una democracia radical exige, entonces, emprender en todos los ámbitos e instituciones una revolución ética, entendida como aquella en la que cada hombre es un interlocutor válido, al que es ineludible tener en cuenta. De igual forma, existen diversas corrientes que realizan una reivindicación del hombre social, donde sin negar la individualidad como persona se aboga por recuperar la dimensión social del ser humano, y la necesidad de construir espacios sociales de diálogo. Entre estas corrientes podemos citar a los comunitaristas (Sandel, 2000) la economía civil (Zamagni y Bruni, 2007), la economía de los comunes (Bollier y

5.- Los requisitos exigidos por la AFEFBC para acceder a la categoría de "Municipio del Bien Común" son:

A. Aprobar el protocolo de adhesión en una sesión ordinaria del pleno del ayuntamiento

$B$. Acreditar al menos una semilla de municipio del bien común

C. Disponer de una relación catalogada de buenas prácticas

D. Contar con el apoyo de la figura de "acompañante facilitador acreditado". Es una persona de la asociación que garantiza que el proceso se realiza de acuerdo con la propuesta de la asociación de la EBC.

E. Inscripción en el Registro de Municipios del Bien Común. Una vez acreditado como municipio del bien común, éste figurará registrado según las semillas conseguidas. Así mismo, las buenas prácticas acreditadas serán publicitadas a través de los canales habituales del movimiento EBC. 
Helfrich, 2014) la economía del buen vivir (Gudynas, 2014), la economía social y solidaria (Corragio, 1998), o la teoría de las capacidades (Nussbaum, 2000).

Asimismo, los propios procesos democráticos son campos de experimentación y nuevas propuestas teórico-prácticas de empoderamiento de la sociedad civil que pueden servir como ejemplos para la implementación de asambleas ciudadanas locales, como es el caso de la democracia 4.0 (JuradoGilabert, 2013), presupuestos participativos (Sintomer, 2005), la gestión de bienes comunales (Ostrom, 2013), etc.

\subsection{Balance del Bien Común Municipal}

En un primer momento el papel de los municipios orientados hacia la EBC es favorecer los cambios institucionales que incorporen en su ámbito a las empresas e instituciones que más beneficien al bienestar de la sociedad. De forma adicional debemos tener en cuenta que el ayuntamiento como organización, despliega toda una serie de actividades y relaciones económicas con otros agentes, puesto que necesita proveerse de recursos varios (energía, agua, materiales, financieros...), genera un impacto medioambiental, contrata trabajadores para la implementación y gestión las políticas públicas, interacciona con los diferentes agentes sociales del municipio, usuarios de sus políticas: ciudadanos, empresas, asociaciones,... y se relaciona con otros municipios. Para ser coherentes con la EBC, lo lógico es que las propias administraciones públicas se sometan al mismo baremo, y midan con un instrumento similar al balance aplicado a las empresas, su contribución al bien común. Esta herramienta se denomina Balance del Bien Común Municipal.

Este es un informe que evalúa el bien común que el ayuntamiento está promoviendo, a través de una serie de indicadores resultantes de analizar los cinco valores de la EBC (dignidad humana, solidaridad, sostenibilidad ecológica, justicia social, transparencia-democracia) con respecto a los diferentes grupos de interés del municipio 6 . El origen de este balance está en el trabajo voluntario de asociados de la EBC en España, de forma que tras diversas jornadas de trabajo colaborativo, se elaboró un balance para los ayuntamientos, que fue aprobado en la Asamblea de la asociación en 2015. A diferencia del balance para las empresas, el Balance Municipal evalúa cada indicador en términos cualitativos y no cuantitativos, de forma que cada uno de ellos se puede lograr en un nivel: senda, avanzado o cumbre.

El resultado sustantivo de este balance es la identificación de Buenas Prácticas que ya vengan desarrollándose desde el ayuntamiento y la identificación de acciones de mejora a desarrollar en el futuro. El objetivo no es ser el mejor municipio, sino crear una nueva cultura gestora, desde la propia

6.- AFEFBC (2015): "Balance del bien común para municipios" Es un documento interno que se puede solicitar a nodo-municipios@economia-del-bien-comun.es, pendiente de publicar en página web. 
autoridad pública, encaminada a plantearse en términos de bien común, cuáles son los resultados, los medios y las mejoras posibles.

Dentro de la lógica de la reforma de los incentivos institucionales de la EBC, Felber (2012) propone que a medio plazo se podría vincular la obtención de buenos resultados en el Balance del Bien Común Municipal a la obtención de ayudas de organismos superiores, por ejemplo ayudas europeas en el contexto de la UE.

\section{Figura 2. La Matriz del Bien Común Municipal}

\begin{tabular}{|c|c|c|c|c|c|}
\hline & $\begin{array}{l}\text { 1. DIGNIDAD } \\
\text { HUMANA }\end{array}$ & 2. SOLIDARIDAD & $\begin{array}{l}\text { 3. SOSTENIBILI- } \\
\text { DAD ECOLÓGICA }\end{array}$ & $\begin{array}{l}\text { 4. JUSTICIA } \\
\text { SOCIAL }\end{array}$ & $\begin{array}{l}\text { 5. PARTICIPACIÓN } \\
\text { DEMOCRÁTICA Y } \\
\text { TRANSPARENCIA }\end{array}$ \\
\hline $\begin{array}{l}\text { A) PROVEEDO- } \\
\text { RES }\end{array}$ & $\begin{array}{l}\text { A1. Gestión ética } \\
\text { de los suministros. }\end{array}$ & $\begin{array}{l}\text { A2. Gestión solidaria } \\
\text { de los suministros. }\end{array}$ & $\begin{array}{l}\text { A3. Gestión sostenible } \\
\text { de los suministros. }\end{array}$ & $\begin{array}{l}\text { A4. Gestión social } \\
\text { de los suministros. }\end{array}$ & $\begin{array}{l}\text { A5. Gestión transpa- } \\
\text { rente de suministros. }\end{array}$ \\
\hline $\begin{array}{l}\text { B) FINANCIADO- } \\
\text { RES }\end{array}$ & $\begin{array}{l}\text { B1. Gestión ética } \\
\text { de las finanzas. }\end{array}$ & $\begin{array}{l}\text { B2. Gestión solida- } \\
\text { ria de las finanzas. }\end{array}$ & $\begin{array}{l}\text { B3. Gestión ecoló- } \\
\text { gica de las finan- } \\
\text { zas. }\end{array}$ & $\begin{array}{l}\text { B4. Gestión social } \\
\text { de las finanzas. }\end{array}$ & $\begin{array}{l}\text { B5. Gestión trans- } \\
\text { parente y democrá- } \\
\text { tica de las finanzas. }\end{array}$ \\
\hline $\begin{array}{l}\text { C) EMPLEADOS } \\
\text { MUNICIPALES }\end{array}$ & $\begin{array}{l}\text { C1. Calidad e igual- } \\
\text { dad en el puesto de } \\
\text { trabajo. }\end{array}$ & $\begin{array}{l}\text { C2. Reparto justo } \\
\text { del volumen de } \\
\text { trabajo. }\end{array}$ & $\begin{array}{l}\text { C3.Comportamiento } \\
\text { ecológico del } \\
\text { equipo humano. }\end{array}$ & $\begin{array}{l}\text { C4. Reparto justo } \\
\text { de la renta. }\end{array}$ & $\begin{array}{l}\text { C5. Democracia } \\
\text { interna y transpa- } \\
\text { rencia. }\end{array}$ \\
\hline $\begin{array}{l}\text { D) CIUDADANOS } \\
\text { / ORGANIZACIO- } \\
\text { NES DEL } \\
\text { MUNICIPIO }\end{array}$ & $\begin{array}{l}\text { D1. Servicios básicos } \\
\text { que garanticen la cali- } \\
\text { dad de vida a todos } \\
\text { los ciudadanos. }\end{array}$ & $\begin{array}{l}\text { D2. Infraestructuras } \\
\text { y medios para la } \\
\text { generación de BC } \\
\text { por los agentes } \\
\text { sociales. }\end{array}$ & $\begin{array}{l}\text { D3. Concepción } \\
\text { ecológica en la } \\
\text { gestión pública. }\end{array}$ & $\begin{array}{l}\text { D4. Fiscalidad } \\
\text { equitativa y políti- } \\
\text { cas para la justicia } \\
\text { social. }\end{array}$ & $\begin{array}{l}\text { D5. Gestión munici- } \\
\text { pal transparente y } \\
\text { participación ciuda- } \\
\text { dana. }\end{array}$ \\
\hline $\begin{array}{l}\text { E) ÁMBITO } \\
\text { SOCIAL }\end{array}$ & $\begin{array}{l}\text { E1. Efecto social. } \\
\text { Fomento de los } \\
\text { valores. }\end{array}$ & $\begin{array}{l}\text { E2. Fomento de } \\
\text { redes con otros } \\
\text { agentes. }\end{array}$ & $\begin{array}{l}\text { E3. Fomento del } \\
\text { comportamiento } \\
\text { ecológico. }\end{array}$ & $\begin{array}{l}\text { E4. Deuda y presu- } \\
\text { puesto sostenible. }\end{array}$ & $\begin{array}{l}\text { E5. Fomento de los } \\
\text { valores democráti- } \\
\text { cos y de la partici- } \\
\text { pación activa. }\end{array}$ \\
\hline
\end{tabular}

FUENTE: AFEFBC (2015).

El balance se concreta en una Matriz del Bien Común Municipal que muestra gráficamente el resultado del proceso que ha supuesto el Balance. En esta Matriz, las columnas corresponden a los cinco valores fundamentales de la EBC: Dignidad Humana; Solidaridad; Sostenibilidad Ecológica; Justicia Social; Participación Democrática y Transparencia. En las filas aparecen los cinco grupos implicados en la acción del ayuntamiento: Proveedores; Financiadores; Empleados Municipales; Ciudadanos / Organizaciones Del Municipio; Ámbito Social. Por tanto la Matriz del Bien Común Municipal tendrá 25 indicadores. Cada uno de ellos recoge en qué medida el ayuntamiento está incorporando y llevando a cabo los principios de la EBC y por tanto, en qué medida puede considerarse un Municipio del Bien Común. 
A continuación vamos a desarrollar brevemente cada uno de los indicadores que componen la Matriz del Bien Común Municipal.

\section{En relación con los proveedores (fila 1):}

- Indicador A1. Gestión ética de los suministros. (Dignidad Humana). Se evalúa cómo el ayuntamiento gestiona el comercio justo y los productos éticos, la elección y las relaciones con proveedores responsables de suministros. Es decir, en qué medida la relación con los proveedores es respetuosa con la dignidad de las personas y promueve unas relaciones laborales dignas. Estas cuestiones pueden concretarse respondiendo a preguntas sobre los modelos de contratación con los proveedores, de qué forma se evalúa la aplicación de la sostenibilidad en sus proveedores o a los productos suministrados al ayuntamiento, y si vienen definidas las características técnicas y ecológicas de los mismos.

- Indicador A2. Gestión solidaria de los suministros. (Solidaridad). En la medida en que el modelo teórico de la EBC promueve el desarrollo local y sostenible, el gobierno municipal debe buscar los mecanismos que fomenten la elección de proveedores de proximidad y de la economía social. Algunas formas de evaluar en qué medida se está siendo solidario en la contratación de proveedores se refieren a cuestiones tales como: ¿Cómo puntúa en los contratos de compra la cercanía del proveedor? ¿Qué sistema de rotación se aplica a los proveedores de su territorio? ¿Qué afinidad tiene los proveedores con la economía social? ¿Cuál es el periodo medio de pago a proveedores?

- Indicador A3. Gestión sostenible de los suministros. (Sostenibilidad Ecológica). Para evaluar el proceso de selección de proveedores en relación a la sostenibilidad ecológica, el ayuntamiento debe utilizar criterios como el grado de sostenibilidad de los proveedores basados en la existencia de certificaciones externas de sostenibilidad, los métodos de reciclaje que utiliza el proveedor y en qué medida éste fomenta los valores de sostenibilidad y ecología.

- Indicador A4. Gestión social de los suministros. (Justicia Social). El ayuntamiento debe tratar de contratar con proveedores que realicen inversiones sociales de sus recursos en el municipio y creen empleo local. En este sentido, una forma de medir la reinversión en el territorio puede ser el porcentaje de sus beneficios que el proveedor destine a proyectos sociales en el territorio.

- Indicador A5. Gestión transparente de los suministros. (Participación Democrática y Transparencia). Gestión de las compras basada en relaciones de confianza, el diálogo y la igualdad de oportunidades. Para ello el criterio fundamental de evaluación de la actividad del ayuntamiento en relación a los proveedores es el grado en que se publican los contratos de adquisiciones que realice el municipio. El mayor valor se alcanzará en este indicador si todos los contratos con proveedores se hacen públicos y el proceso de adjudicación es totalmente transparente. 


\section{En relación con los financiadores (fila 2):}

- Indicador B1. Gestión ética de las finanzas. (Dignidad Humana). La entidad municipal puede elegir entidades financieras respetuosas con la dignidad de las personas y que demuestren unas relaciones laborales dignas. Esta consideración teórica puede evaluarse teniendo en cuenta los siguientes criterios: ¿Con qué criterio se selecciona la entidad bancaria para la gestión de los fondos del municipio? ¿Tiene acuerdos de inversión social con la entidad bancaria con la que trabaja? ¿Participa como promotor en alguna propuesta de banca ética?

- Indicador B2. Gestión solidaria de las finanzas. (Solidaridad). La gestión municipal ayudará en mayor medida a promover el bien común en la medida que utilice para su financiación y en sus transacciones económicas entidades de la Banca ética, entidades financieras cooperativas y de la economía social. Para poder valorar en qué medida se está cumpliendo con este objetivo, se propone dos criterios: primero, el análisis de cómo desde la gestión municipal se fomenta a las entidades financieras locales a promover acciones en beneficio de la comunidad; y segundo, la medición de los préstamos solidarios a proyectos sociales e inversiones socialmente responsables que realiza la entidad financiera con la que trabaja habitualmente el ayuntamiento.

- Indicador B3. Gestión ecológica de las finanzas. (Sostenibilidad Ecológica). El ayuntamiento debe tratar de elegir entidades que gestionan ecológicamente sus residuos y / 0 inviertan en proyectos de impacto ambiental positivo. Los criterios aplicables en este caso para valorar la acción municipal pueden ser: el compromiso de la entidad bancaria con la gestión de sus residuos; la realización por parte de la entidad financiera de acciones propiciando el desarrollo ecológicamente sostenible; y la inversión por parte de la entidad financiera en proyectos de energías renovables.

- Indicador B4. Gestión social de las finanzas. (Justicia Social). Del mismo modo, la gestión bajo el valor de la justicia social requiere una relación con entidades financieras que reinvierten en el territorio, como por ejemplo, realizar préstamos solidarios a proyectos sociales.

- Indicador B5. Gestión transparente y democrática de las finanzas. (Participación Democrática y Transparencia). Con este indicador se trata de evaluar en qué medida el ayuntamiento ha puesto en marcha mecanismos de control sobre la transparencia de las entidades financieras con las que trabaja. La existencia de estos mecanismos implicará la elección de entidades transparentes en sus inversiones y en la captación de pasivo. Puede emplearse dos criterios: en primer lugar, el trato que la entidad bancaria realiza con los ciudadanos con problemas financieros (desahucios, recibos luz, etc.). En segundo lugar, las inversiones y captaciones de pasivos que la entidad bancaria realiza de los fondos públicos que el municipio aporta y la disponibilidad de la información del destino de los fondos. 


\section{En relación con los empleados municipales (fila 3):}

- Indicador C1. Calidad e igualdad en el puesto de trabajo. (Dignidad Humana). Aunque las relaciones laborales se rigen en gran medida por la legislación nacional y el Convenio Colectivo, sigue habiendo un gran margen para la gestión ética de los empleados municipales. Por tanto, este indicador evalúa en qué medidas las relaciones laborales en el ayuntamiento están orientadas a que los trabajadores posean condiciones de trabajo dignas, saludables y respetuosas. Existen muchos criterios para tratar de facilitar la medición de la aportación de un Ayuntamiento al Bien Común en relación a este principio. A continuación se presentan algunos de ellos: Gestión de los horarios de trabajo: horarios flexibles; consensuados directamente con el trabajador o sus representante; ergonomía del puesto de trabajo, facilidad de elección del puesto, espacios de relajación, etc. Igualdad efectiva en el trato entre hombres y mujeres, que incluye la elaboración de un informe de igualdad, la inversión en formación sobre diversidad y género y la discriminación positiva hasta alcanzar determinadas cuotas en la contratación, etc.

- Indicador C2. Reparto justo del volumen de trabajo (Solidaridad). Este indicador muestra en qué medida está la gestión municipal comprometida con estrategias de reparto del trabajo que reduzcan el desempleo y promuevan la empleabilidad. En épocas de crisis, estas estrategias pueden materializarse en la reducción de la jornada laboral para el mantenimiento del empleo.

- Indicador C3. Comportamiento ecológico del equipo humano. (Sostenibilidad Ecológica). El objetivo es promover entre los empleados municipales una cultura organizacional respetuosa con el entorno natural, la movilidad sostenible, hábitos de vida sana... Para evaluar el grado de implicación de los gestores locales con este principio se pueden tratar de cuantificar la medida en que la administración del municipio está implicada en cuestiones tales como la alimentación durante la jornada laboral del personal empleado y el fomento de buenas costumbres; la movilidad de los empleados durante la jornada laboral; la existencia de programas de concienciación y de acción para todos los trabajadores y de medidas innovadoras y participativas (servicios verdes); o el control de la Huella ecológica (de Carbono) de los trabajadores municipales.

- Indicador C4. Reparto justo de la renta (Justicia Social). En relación a la retribución equitativa, responsable y transparente dentro del ámbito municipal tres son los criterios que pueden dar muestra de en qué medida está aportando el ayuntamiento al fomento del bien común: cuantía del salario mínimo, del salario máximo, y por tanto, diferencia de salarios dentro del Ayuntamiento y en relación a otros salarios similares a nivel nacional.

- Indicador C5. Democracia interna y transparencia (Participación Democrática y Transparencia). A lo largo del presente artículo se ha hecho hincapié de forma reiterada en la importancia de la toma de decisiones democráticas para el fomento de un auténtico bien común. La primera de las estrategias descritas para la creación de un Municipio del Bien Común tiene que ver precisamente con esa participación ciudadana. Ahora toca aplicar este principio a la gestión interna del ayuntamiento. Por 
tanto, los indicadores de transparencia tienen que ver con la existencia o no de procesos democráticos en la toma de decisiones y en la selección del personal; la consulta popular a través de presupuestos participativos; y el grado de transparencia en que las cuestiones municipales son accesibles a los ciudadanos. En relación a este último criterio, el objetivo deseable es que todos los datos municipales sean transparentes al $100 \%$ y por tanto se habiliten las herramientas necesarias para que puedan ser consultados en cualquier momento por todos los ciudadanos.

\section{En relación con los ciudadanos y organizaciones del municipio, como beneficiarios de la gestión pública (fila 4):}

El ayuntamiento debe valorar cuál es su contribución en su relación con ciudadanos y organizaciones del municipio como "prestador" de servicios y gestor de los recursos como administración pública.

- Indicador D1. Servicios básicos que garanticen la calidad de vida a todos los ciudadanos. (Dignidad Humana). Una de las funciones prioritarias del ayuntamiento será el desarrollo de políticas que garanticen la calidad de vida de sus ciudadanos y para ello deberá evaluar, en una primera instancia, en qué medida están orientados los servicios hacia el ciudadano y se promueve la co-creación de servicios públicos. Este indicador sugiere autoevaluarse en torno a las siguientes cuestiones: ¿Qué programa de eliminación de barreras arquitectónicas se están realizando? ¿Cómo contribuye el Ayuntamiento a la seguridad ciudadana? ¿Cómo contribuye el Ayuntamiento a la elevación o mejora de calidad de vida? ¿Cómo participa el Ayuntamiento en la atención a los más desfavorecidos? ¿Cómo contribuye el Ayuntamiento en el incremento de calidad de vida de todos sus ciudadanos?

- Indicador D2. Infraestructuras y medios para la generación del bien común por los agentes sociales (Solidaridad). Parte de la responsabilidad del desarrollo del bien común consiste en promover mecanismos de interrelación entre los diferentes agentes sociales del municipio, para que sean ellos mismos los que fomenten las acciones solidarias. En este sentido, el ayuntamiento debe facilitar las estructuras y medios, y alentar las acciones colaborativas. Su evaluación se puede realizar reflexionando sobre los espacios dinámicos disponibles para encuentros que pone el ayuntamiento a disposición de los ciudadanos, el fomento de la creación de mercados de proximidad, el impulso del sistema asociativo del municipio, la realización de algún tipo de organización del banco del tiempo o la gestión de la exclusión social.

- Indicador D3. Concepción ecológica en todos los servicios municipales y sostenibilidad de los elementos patrimoniales. (Sostenibilidad Ecológica). Entre los aspectos que se valoran está la existencia de sistemas de potenciación y de formación entre la población para favorecer la cultura del reciclado y el desarrollo ecológico en el municipio. Asimismo, la propia gestión de los servicios municipales debería ser aplicada de la forma más ecológica, aplicando medidas de ahorro energético y empleando energías renovables. Otro elemento a tener en cuenta es la gestión sostenible de los elementos patrimoniales municipales, en especial los espacios públicos donde la colaboración ciudadana es funda- 
mental. Por último, el ayuntamiento puede realizar una defensa del patrimonio tanto material como inmaterial.

- Indicador D4. Fiscalidad municipal equitativa y políticas para la justicia social. (Justicia Social). Una de las tareas que debe acometer un ayuntamiento consiste en evitar situaciones de necesidad presentes y futuras entre los ciudadanos, promoviendo la equidad en la distribución de riqueza. La fiscalidad municipal tiene que estar distribuida con equidad, para evitar situaciones de necesidad a los ciudadanos. Por ello, las cuestiones que se plantean son: ¿Qué modelo de fiscalidad genera un equilibrio en las diferentes rentas de los ciudadanos? ¿Qué formación realiza para la búsqueda activa de empleo? ¿Qué políticas activas se realizan para la resolución de necesidades económicas de precariedad social? ¿Qué criterios se aplican para asegurar la justicia social en todas las políticas dirigidas a los más necesitados?

- Indicador D5. Gestión municipal transparente y con participación ciudadana. (Participación Democrática y Transparencia). La transparencia es necesaria para que la ciudadanía tenga la información requerida para ejercer el control sobre la gestión pública. Además, la participación ciudadana en sus diversas formas es un componente esencial de la calidad democrática, por ello el aumento de los estándares de transparencia municipal y de participación ciudadana fomentan el bien común. Entre otros aspectos se valora: ¿Qué sistema se sigue para la solicitud para un préstamo de espacios públicos? ¿Qué políticas de presupuesto participativo y/o consultas ciudadanas del gasto realizan? ¿Qué participación ciudadana realizan para encontrar soluciones a los problemas del municipio? ¿Cómo realizan la transparencia y publicación de los gastos municipales? ¿Cómo se articula la participación ciudadana en la prestación de los servicios públicos? ¿Se fomenta una cultura de la pluralidad?

\section{En relación al ámbito social y el fomento de los valores (fila 5):}

El ayuntamiento puede ejercer el papel de mediador y facilitador de creación de redes entre y con el resto de agentes que están en el territorio.

- Indicador E1. Efecto social. Fomento de los valores éticos. (Dignidad). El ayuntamiento puede fomentar campañas que impulsen la aplicación y desarrollo de los Derechos Humanos, co-crear plataformas contra la discriminación en la sociedad, apoyar y potenciar proyectos sociales e innovadores a favor de la participación basados en la autogestión, o favorecer el urbanismo solidario.

- Indicador E2. Fomento de redes con otros agentes dentro y fuera del municipio (Solidaridad). Es importante el cambio de cultura, donde la administración pública no es la proveedora de servicios de acuerdo con sus criterios, si no que ofrece su colaboración para promocionar la cooperación entre los diferentes agentes para compartir conocimiento, financiación y actuaciones conjuntas. Puede también mancomunar esfuerzos entre municipios cercanos para la dignidad humana, o fomentar los convenios y redes con asociaciones y organizaciones para impulsar la solidaridad. 
- Indicador E3. Fomento del comportamiento ecológico. (Sostenibilidad ecológica). La sostenibilidad ecológica es responsabilidad de todos, por ello el ayuntamiento puede mancomunar esfuerzos para un programa de apoyo sostenible de los espacios ecológicos municipales, fomentar el ahorro energético del municipio y el uso de energías renovables entre la población y favorecer estilos de vida respetuosos con el medio ambiente.

- Indicador E4. Deuda sostenible para no dejar cargas a generaciones futuras. (Justicia Social). El Ayuntamiento no puede realizar una gestión irresponsable que comprometa la prestación de servicios para las generaciones futuras, por ello debe contar con un presupuesto sostenible, y con un plan de amortización de la deuda acorde con éste.

- Indicador E5. Fomento de los valores democráticos y de la participación activa en la gestión del municipio. (Participación democrática y transparencia). El ayuntamiento debería conocer la evaluación del bienestar de los ciudadanos, y por ello puede realizar una encuesta con carácter bianual.

\section{El Balance del Bien Común Municipal y otros indicadores de la responsabilidad del sector público:}

El Balance del Bien Común Municipal es una herramienta de evaluación del impacto de las actuaciones de la administración pública sobre los cinco valores propuestos desde la EBC, cuando se relaciona con los diferentes grupos de interés. En concreto, se centra por un lado en la gestión interna en la toma de decisiones (respecto a los financiadores, proveedores y trabajadores), y por otro, en cómo las decisiones públicas afectan también al ámbito externo del municipio (a los ciudadanos y al resto de la sociedad). Se constituye por tanto en una herramienta de gestión y de rendimiento de cuentas, cercana a la responsabilidad social del sector público.

En relación a esta noción de responsabilidad del sector público, la teoría de la administración pública (Andrews et al. 2011; Pierre y Peters, 2000) la plantea como una respuesta a una sociedad que demanda que el sector público, además de cumplir los aspectos normativos y perseguir la eficacia, debe considerar los posibles impactos económicos, sociales, ambientales y de reputación de su actividad, y responder a los objetivos de los diferentes grupos de interés, dándoles participación en los procesos de toma de decisiones.

Cabe destacar que la responsabilidad social (RS) en el ámbito privado empresarial tiene una larga trayectoria (Garrriga y Melé, 2004), pero este concepto ha sido ajeno al sector público hasta principios de este siglo, puesto que la propia naturaleza de la actividad pública la hacía merecedora de su orientación al interés público. De hecho, la preocupación por el sector público se centra inicialmente en la promoción de la responsabilidad social o la sostenibilidad empresarial, para posteriormente, como indicaba el consejo de la UE en su Libro verde de la Responsabilidad Social, la necesidad de incorporar los principios de la RS en la propia Administración (Canyelles, 2011). Esta propuesta también se ha visto reflejada en el caso español en diferentes normativas que indican la misma recomendación, pero 
no su carácter obligatorio. En esta dirección, la Estrategia Española de Responsabilidad Social para empresas, Administraciones Públicas y el resto de organizaciones 2014-2020, plantea armonizar las distintas actuaciones en materia de RS en las empresas y en la Administración. Los principios fundamentales en los que se basa la estrategia son voluntariedad, creación de valor para toda la sociedad, competitividad, mayor cohesión social, transparencia, sostenibilidad y protección de los derechos humanos (Melle Hernández, 2014).

Desde la perspectiva de la medición de los impactos de la actividad de la administración pública, los modelos tomados por referencia proceden de la evolución de la RS en el sector privado. Siguiendo el informe de AEVAL (2011), se pueden plantear cuatro métodos evaluativos aplicables a la actividad económico, social y medioambiental de la actividad de las administraciones públicas. En el primer nivel de medición se sitúan diversas iniciativas en distintos ámbitos internacionales que ofrecen unos criterios generales de la responsabilidad social para conseguir la sostenibilidad, tales como Naciones Unidas (Pacto Mundial), Organización Internacional del Trabajo (Declaración Tripartita), OCDE (Directrices para Empresas Multinacionales) o la Unión Europea (Libro Verde).

El segundo nivel de medición se centra en la implementación mediante unas guías que asesoran sobre el proceso de medición y de difusión de la información de sostenibilidad o RS de las administraciones públicas, como es el GRI que cuenta con una adaptación para el sector público.

El tercer nivel de medición es la integración de la sostenibilidad en el propio sistema de gestión de la calidad organizativa. Como ejemplo se pueden destacar dos modelos evaluativos en el ámbito público local, la norma UNE 66182:2015 (AENOR, 2016) y el modelo europeo, CAF 2013 (AEVAL, 2013). La Norma técnica UNE 66182 "Guía para la evaluación integral del gobierno local y el desarrollo como ciudad inteligente" tiene como objetivo proporcionar a los gobiernos locales una metodología asequible y práctica para fijar e incrementar su nivel de confiabilidad y facilitar la integración en sus servicios de la perspectiva de ciudades inteligentes (AENOR, 2016). Se propone un método de doble evaluación (operativa y directiva) basado en evidencias en los siguientes ámbitos: desarrollo institucional para el buen gobierno; desarrollo económico sostenible; desarrollo social incluyente y desarrollo ambiental sostenible.

La última categoría en la medición de la actividad de responsabilidad social de las administraciones públicas son las herramientas que se centran en un sistema de gestión específico de la sostenibilidad, como es la Guía ISO 26000, que se ha adaptado al ámbito local mediante la certificación AENOR IQNet SR10 (AENOR, 2012).

El balance del bien común del ayuntamiento se puede considerar una herramienta que se encuadra en esta última categoría como un modelo de gestión y de rendición de cuentas de un ámbito específico de la organización. Sin embargo, hay cuatro elementos diferenciadores entre las propuestas de medición del impacto económico, social y medioambiental de las actividades de las administraciones públicas (y en concreto en el ámbito municipal) y la propuesta de la Economía del Bien Común. 
El primer elemento diferenciador es el objeto de evaluación: el bien común. Si bien la EBC comparte con la responsabilidad social pública principios básicos como son la participación, la transparencia y la sostenibilidad, en la EBC este bien común se articula y da protagonismo a los valores de la dignidad (en un sentido amplio y no sólo restringido a las relaciones laborales), y a la justicia social y la solidaridad, elementos que no tienen la misma relevancia en las otras evaluaciones, o ni siquiera están presentes.

El segundo es la metodología de definición del bien común municipal, ya que en la EBC se fundamenta en un proceso participativo no apriorístico y que puede variar de territorio a territorio. Por tanto en ningún caso es considerado un objetivo determinado por la administración pública para el municipio, sino más bien un objetivo escogido y definido por los integrantes del municipio que se presenta a la administración para el desarrollo y ayuda a su implementación.

El tercer elemento diferenciador es que la responsabilidad social pública entra en una lógica voluntarista, donde esta responsabilidad social aparece como un "valor añadido" al cumplimiento de la norma legal (MINHAFP, 2013). Sin embargo, la reflexión de la EBC es que cualquier organización, incluida la administración pública, tiene que plantearse como organización cuál es su contribución al bien común, y por tanto se convierte en la motivación organizacional fundamental.

Por último, otro elemento que diferencia las propuestas de responsabilidad social de las administraciones públicas extendidas en la actualidad y la propuesta de la EBC, estriba en la visión del desarrollo basada en la competitividad que perdura en los enfoques de RS de las administraciones. Por ejemplo, en la exposición de motivos de la Normativa Estatal y Europea, aparece la RS como herramienta de competitividad. Esta visión es una herencia del concepto de responsabilidad social empresarial (RSE), donde las estrategias de sostenibilidad en muchos casos se defienden como generadoras de ventajas competitivas en el mercado. Frente a esa idea de competencia por la obtención y uso de los recursos, la EBC defiende que el elemento dinamizador de la sociedad es la cooperación.

Por último, en relación a la medición del impacto de la actividad de las organizaciones cabe citar las auditorias sociales realizadas desde la economía social y solidaria, que comparten con la EBC la visión de que el fin de la empresa no es la maximización de beneficios, sino que este es un medio para generar bien común, pero sin embargo no han trasladado sus sistemas evaluativos a la gestión pública.

\subsection{Promoción de la EBC en organizaciones privadas, empresas, ONGs, etc.}

Una tercera estrategia de fomento de la EBC es, según la propuesta de Felber (2012:225), que el ayuntamiento invite al empresariado del lugar a realizar el balance del bien común. Para incentivar esta actuación la EBC propone que el ayuntamiento financie la consultoría y la auditoría necesarias para realizar el balance, promueva la información pública de los resultados y buenas prácticas de estas empresas, y se las priorice en la contratación pública (Felber, 2012:226). 
La ASFEBC considera que un ayuntamiento está generando una "semilla" si extiende la promoción de la EBC a todo tipo de organizaciones que desarrollen su actividad en el municipio, como pueden ser asociaciones, ONGs, fundaciones, etc.

La transformación de un municipio hacia el bien común requiere sobre todo de motivación intrínseca por parte de las personas y colectivos que lo integran, pero desde un ayuntamiento se pueden generar incentivos adicionales para motivar las buenas prácticas. Son prácticas generadoras de bien común, que pueden tomar formas diversas, donde el papel del sector público es de "facilitador" para su desarrollo. La EBC, como propuesta teórica y práctica no reclama como propio el "bien común", por el contrario, entiende que la generación de éste se puede realizar de muchas formas y que existen muchas interrelaciones entre diversas corrientes que permiten un enriquecimiento mutuo. De hecho, la ASFEBC está desarrollando un trabajo de recopilación de buenas prácticas, que se pueden considerar generadoras del bien común. Muchas de éstas vienen propiciadas por corrientes anteriores, como por ejemplo la creación de monedas sociales, mercados sociales, las empresas cooperativas (desde la economía social y solidaria), favorecer los bancos del tiempo, el fomento del empleo de espacios públicos por asociaciones vecinales (de acuerdo con la propuesta de los comunes), etc.

Dentro de esta estrategia de promoción del bien común, tiene especial incidencia la gestión por parte del ayuntamiento de la normativa reguladora de la contratación pública. Más allá del precio y la libre concurrencia, la contratación pública se revela como un instrumento potente del que disponen las instituciones públicas, en general, y las locales en particular para promover, evaluar e incorporar otros criterios evaluativos.

La Administración Pública se convierte así un agente importante al que cabe exigir eficacia y eficiencia, entendida ésta no sólo en términos monetarios sino también sociales ya que, como indica Bernete (2013): a) es gestora de fondos y presupuestos públicos y debe impulsar efectos sociales y de empleo; b) es consumidora y por tanto debe promover un fin ético en sus compras; c) y ha de actuar como referente para el resto de agentes sociales y económicos llamados a ejercer su responsabilidad social.

Aunque el marco de actuación local está delimitado por normativas de orden superior, el ayuntamiento cuenta sin embargo con diferentes herramientas para crear incentivos fiscales que favorezcan la promoción del bien común, en especial las cláusulas sociales?.

Esta superación del precio como criterio de eficacia parece tener su punto de inflexión (Bernete, 2013) con una sentencia del Tribunal Supremo (23 de mayo de 1997) en la que se expresa: «La administración no está obligada a aceptar el mejor precio, sino la oferta más favorable al interés público».

7.- García Calvente, Y. (2015) ofrece un análisis detallado de la constitucionalidad de los incentivos fiscales propuestos por la Economía del Bien Común, para el caso de España. 
En ese mismo año el Comité Económico y Social Europeo aprobó el 29 de mayo de 1997 un Dictamen sobre contratación pública en el que se indicaba: “....el criterio del precio no es el único determinante. Teniendo en cuenta las prioridades comunitarias, especialmente en materia social, las autoridades públicas adjudicatarias podrán integrar estas preocupaciones en los contratos que se realicen". A partir de aquí se ha ido desarrollando una normativa al respecto hasta desembocar en la directiva europea de 2014 donde recoge expresamente el empleo de la "la contratación pública en apoyo de objetivos sociales comunes".

\subsection{El desarrollo participativo de un "Índice del Bien Común Municipal"}

El Índice del Bien Común municipal (IBCM) es una herramienta mediante la cual la ciudadanía identifica los aspectos del municipio que tienen mayor influencia sobre su propia percepción del bien común. La metodología de construcción de este índice se debería basar en procedimientos de participación ciudadana que podrían determinar los factores (entre diez y veinte) más importantes de la calidad de vida. El objetivo no es crear una herramienta para comparar la calidad de los municipios, sino diseñar un índice que señale cómo conseguir mejoras en aquellos factores de la calidad de vida que realmente importan a los ciudadanos del municipio. En función de este índice se debería poder medir las medidas políticas aplicadas (Felber, 2012). ${ }^{8}$

La definición de "nuestro" bien común y como éste contribuye a nuestra calidad de vida es una tarea propia de la comunidad, y que debería centrar el debate público en los aspectos de la vida en y con la comunidad afectada.

La creación de un IBCM es un proceso todavía abierto. La EBC no ha desarrollado hasta ahora una metodología propia y específica para la construcción de este índice. Por ello, a continuación vamos a presentar dos componentes que pueden ayudar a desarrollar esa metodología de creación del IBCM.

En primer lugar, la metodología denominada Investigación Acción-Participativa (IAP) puede ofrecer el marco teórico y práctico para la creación del IMBC. La IAP es un proceso de investigación, producción de conocimiento e intervención que parte de problemas sociales específicos buscando transformarlos y concretar un proceso colectivo de producción del saber (Frizzo, 2008). Esta metodología permite a los interlocutores construir significados compartidos, a partir del reconocimiento como sujetos de pensamiento, de acción y de transformación (Freire, 1998). Es decir, en relación al ámbito del que estamos tratando (la creación de un índice del bien común municipal) el vecindario no es el sujeto pasivo a "investigar" por los técnicos del ayuntamiento, apoyados por un marco teórico de la academia, sino que dicho vecindario es a la vez el sujeto investigador.

8.- En el libro no aparece la propuesta de la necesidad de participación ciudadana en la propia construcción del índice, elemento que sí es explícito en el protocolo que la organización de la EBC propone, escrito por Felber, http://economia-del-biencomun.org/es/content/municipioregion\#overlay-context=es/node/17 
La propuesta metodológica del IMBC también podría enriquecerse con las propuestas recogidas en el proyecto "Community Quality-of-Life Indicators" (Rahtz, Sirgy y Phillips, 2013). Este proyecto, también defiende la creación de índices mediante procesos participativos (Rondinella, Segre y Zola, 2015) y además delimita su campo de estudio a "community well-being", que desde nuestra perspectiva en un término muy cercano al "bien común", pues se centra en evaluar cuáles son los elementos que hacen que vivir en y con nuestra comunidad afecte a nuestra calidad de vida.

Haworth y Graham (2007) explican que muchas de las capacidades para el bienestar se fundamentan en las relaciones sociales y la organización social y no el individuo, y mucho menos en recursos que son sólo de propiedad individual. Por ello, Rapley (2003) afirma que la calidad de vida es una cuestión política y local, más que una cuestión universal, abstracta, apolítica o académica.

La construcción de indicadores de "community well-being" para el desarrollo local basado en la participación de la comunidad deben tener cinco características, propuestas por Salvaris (2000):

1. Es un medio para integrar objetivos económicos, sociales y medioambientales en relación a una visión compartida del progreso o el bienestar, y una visión para el futuro.

2. Se desarrollan objetivos concretos para poder medir el progreso, alguno de ellos se expresan en categorías estadísticas y en medidas convencionales, mientras que otros están relacionados con aspectos menos convencionales.

3. El inicio, el desarrollo y el seguimiento de los indicadores se debe realizar mediante procesos de participación de toda la comunidad que pueden contar con el apoyo de especialistas.

4. Es un proyecto a largo plazo que puede suponer un proceso de 5 años.

5. Las relaciones formales entre el gobierno y la comunidad son importantes para su desempeño, pero es cierto que a veces, por razones de diferente índole, éstas se convierten en un obstáculo.

\subsection{Creación de una Región del Bien Común}

Por último, a medio plazo, varios municipios del bien común pueden reunirse en su área geográfica para constituir regiones del bien común. De esta manera, los municipios pueden aprender juntos y complementarse mutuamente generando redes de cooperación. Este planteamiento cambia la filosofía de territorios compitiendo a territorios cooperando, y de la búsqueda de la máxima producción a la consecución del bienestar mediante el bien común.

Esta propuesta está en consonancia con la reivindicación de Daly y Cobbs (1989) de la necesidad de repensar de forma colectiva la sostenibilidad social desde una perspectiva desde abajo a arriba, mediante una "comunidad de comunidades". 
Esta estrategia de creación de redes no es nueva, a modo de ejemplo, la UE cuenta con una red denominada grupos de desarrollo rural (GDR). Estas son organizaciones sin ánimo de lucro que funcionan como dinamizadores territoriales y mediadores entre los diferentes agentes socio-económicos del territorio, para fortalecer los lazos y relaciones de cooperación.

\section{5.- Conclusiones}

Existen múltiples corrientes, desde perspectivas diferentes (económica, social y medioambiental), que apuntan hacia una necesidad de cambio en la forma de entender la política desde lo local que se concreta en diversas iniciativas municipales, ciudadanas, locales o regionales que buscan la dignificación de la política y la economía.

En términos generales, la EBC pretende servir como comienzo para pensar de otra manera: para entender la política como un instrumento que incremente el bien común y que contribuya a enriquecer aquellos valores que la EBC considera positivos y favorables para nuestra calidad de vida. Cuando el responsable de una empresa, una organización o un municipio elabora el balance del bien común, se obliga a pensar de manera minuciosa en la forma de mejorar la vida y el bienestar de las personas y de respetar su entorno más cercano. Por tanto, la EBC ofrece un discurso teórico alternativo al de la maximización de producción y de la competencia y sobre todo, ofrece una herramienta práctica para llevar a cabo el cambio hacia esa nueva manera de pensar y actuar.

También plantea un reto a la ciudadanía como es la reflexión sobre cuáles son los valores básicos para la buena vida en común. Este planteamiento se fundamenta en la idea de que las personas podemos dialogar y construir espacios comunes, creando intereses comunes, no solo "intercambiando" intereses individuales. Esos intereses comunes se pueden buscar en los valores humanos, siendo los cinco valores propuestos por la EBC un punto de partida para construir un marco "constitucional" de convivencia. A partir de ahí, de nuevo la ciudadanía debe plantearse ¿cuáles son los aspectos básicos de la convivencia? Esta sería la guía en la que debería basarse la gestión política. Desde este proceso de reflexión, la EBC pretende fomentar realmente el fortalecimiento de la democracia, como elemento básico de construcción social.

Otra aportación fundamental del modelo económico-social de la EBC es la métrica del bien común, pues "lo que medimos afecta lo que hacemos, si no medimos lo correcto, no haremos lo correcto" (Stiglitz, Sen y Fitoussi, 2013:1). Es una métrica de lo que las personas quieren para su convivencia, ya que el índice del bien común municipal puede servir como verdadera brújula de evaluación de las políticas locales. Además, el balance del bien común del propio ayuntamiento supone una nueva herramienta de gestión pública. Tanto el Índice del bien común como el balance del bien común del ayun- 
tamiento y de las empresas del municipio se muestran, de esta manera, como herramientas efectivas de transformación real.

Sin duda esto supone un gran reto en el ámbito municipal, puesto que la discrecionalidad normativa del ayuntamiento es muy limitada ya que no tiene plenas potestades legislativas (que corresponden a otras administraciones). Pero, en sentido contrario, lo local es el ámbito más cercano a las personas, desde dónde se pueden gestar los cambios, y desde donde es más fácil crear nuevos proyectos encaminados a la generación del bien común. La EBC no sólo ofrece un marco de políticas locales, sino que aspira a construir un modelo económico alternativo en el ámbito nacional, y trascender a entidades superiores.

Así, el papel del sector público cobra especial relevancia a la hora de facilitar la co-creación, y no la imposición, de otro modo de economía. Es importante destacar que esta propuesta no defiende más sector público, sino "otro sector público". Una administración pública que ceda protagonismo a la sociedad civil, mediante una mayor participación democrática y la facilitación de espacios para el desarrollo de proyectos colectivos. Esta administración pública cuenta además con otras herramientas básicas como son la normativa, el gasto público y la fiscalidad para crear incentivos que favorezcan el fomento del bien común.

Uno de los elementos básicos del modelo de la EBC es el convencimiento de que esté es un proyecto abierto, ya que su propia filosofía legitima las decisiones en función de la democracia, dentro del respeto a los derechos humanos. Por tanto, el planteamiento teórico de la economía del bien común no es un modelo acabado. Cabe recordar que esta propuesta teórica general aparece en el 2010, y ya en el 2014 se produce la primera reunión de municipios del bien común. El proceso continúa en marcha...

Por tanto, la propuesta que hemos presentado en este trabajo requiere de una mayor profundización y un desarrollo en diversos aspectos: formas de participación democrática, construcción participativa del índice, modificación de la cultura de la gestión pública, concienciación ciudadana, creación de redes empresariales y sociales fundamentadas en la cooperación y no en la competencia, etc.

Para esta tarea la EBC se puede apoyar en una gran variedad de otras propuestas teóricas y prácticas existentes en el ámbito de la economía: economía social y solidaría, circular, colaborativa, de los comunes, de los cuidados, ecofeminismo, etc.; de la política: presupuestos participativos, democracia líquida, etc.; conecta y necesita además con el derecho, la antropología, la educación, la sociología, etc. La EBC se presenta en su naturaleza como un modelo holístico, porque se pregunta cómo la persona puede vivir mejor en sociedad, y la respuesta exige, por tanto buscar respuesta en todos los campos del saber.

Nuestro trabajo presenta por primera vez la aplicación de la Economía del Bien Común al ámbito Municipal, detallando las estrategias que debe seguir un municipio para llegar a ser Municipio del Bien 
Común. En la presentación de esta propuesta hemos descrito los indicadores que utiliza la Matriz del Bien Común. Ésta es una herramienta de evaluación novedosa por su objeto de evaluación, el bien común, por su sujeto, la administración pública, y por su vocación transformadora de la sociedad. Futuros trabajos de investigación pueden comparar los indicadores de la Matriz del Bien Común con algunos otros que ya se están utilizando en el ámbito municipal para tratar de mejorar dichos indicadores y reflexionar sobre la idoneidad de los mismos. Por tanto este trabajo se presenta como una primera aportación a la reflexión y el debate sobre la propuesta de la Economía del Bien Común en relación a otros aportes críticos que consideran las dimensiones social, económica y ambiental del municipio.

También esperamos que este artículo sirva de documento de trabajo para que la comunidad científica desde los diversos y específicos campos del saber y, sobre todo, las empresas, entidades sociales y organismos públicos contribuyan a la creación de un espacio social y económico que realmente promueva el bien común desde el ámbito municipal para todos los ciudadanos.

\section{Bibliografía}

ACOSTA, A. \& MARTÍNEZ, E. (2009): El buen vivir. Una vía para el desarrollo, Editorial Universidad Bolivariana, Santiago.

AENOR (2012): IQNet SR10, El Sistema Internacional de Responsabilidad Social. Consultado el 4 de Julio de 2017 en:

$\mathrm{http}: / /$ www.aenor.es/aenor/actualidad/actualidad/noticias.asp?campo=1\&codigo=22406\&tipon=\# .WVW-1-ILeUm.

AENOR (2016): Guía para la evaluación integral del gobierno municipal y el desarrollo como ciudad inteligente. Consultado el 4 de Julio de 2017 en: http://www.aenor.es/aenor/certificacion/calidad/calidad_servicios_gobierno_municipal.asp\#.WVw8RulLeUI

AEVAL (2011): Hacia una administración pública sostenible, Agencia Estatal de Evaluación de las Políticas Públicas y la Calidad de los Servicios, Ministerio de Política Territorial y Administración Pública, Madrid.

AEVAL (2013): El marco común de evaluación. Mejora de las organizaciones públicas por medio de la autoevaluación. Consultado el 4 de Julio de 2017 en: http://www.aeval.es/export/sites/aeval/comun/pdf/calidad/guias/Guia_CAF_2013.pdf.

ANDREWS, R., COWELL, R. \& DOWNE, J. (2011): "Promoting Civic Culture by Supporting Citizenship: What Difference Can Local Government Make?", Public Administration, 89 (2), 595-610. 
ARGANDOÑA, A. (2011): El bien común, Documento de Investigación DI-937, IESE Business School - Cátedra "la Caixa" de Responsabilidad Social de la Empresa y Gobierno Corporativo.

ARNSTEIN, S.R. (1969): "A ladder of citizen participation", Journal of the American Institute of planners, 35 (4), 216-224.

ASOCIACIÓN DE ECONOMÍA DEL BIEN COMÚN (2014): El municipio del bien común, consultado el 1 de julio de 2016, http://economia-del-bien-comun.org/es/content/municipioregion\#overlaycontext=es/node/17.

AFEFBC (2015): "Balance del bien común para municipios". Documento interno que se puede solicitar a nodo-municipios@economia-del-bien-comun.es

ASFEBC (2015): "Protocolo para declaración de municipios del bien común". Documento aprobado en la Segunda Asamblea General de la Asociación Federal Española para el Fomento de la Economía del Bien Común, el 31/05/2015, documento interno de la ASFEBC, se puede solicitar a nodo-municipios@economia-del-bien-comun.es.

BAUMAN, Z. (2001): La sociedad individualizada, Cátedra, Madrid.

BERNETE, J. (2013): "Cláusulas sociales en la contratación pública: nuevos instrumentos para el fomento del empleo a nivel local", Cuadernos de Trabajo Social, 26(1), 85-94.

BOLLIER, D. \& HELFRICH, S. (ed.) (2014): The wealth of the commons: A world beyond market and state, Levellers Press.

BRAUNGART, M. \& MCDONOUGH, W. (2005): Cradle to Cradle: Remaking the Way We Make Things, Madrid: McGraw-Hill.

BRUQUÉ, Q. (2009): Calidad democrática: de la debilidad a la fuerza deliberativa. En: Parés, M. (ed.) Participación y calidad democrática: evaluando las nuevas formas de democracia participativa, Ariel, Barcelona.

BUSTELO, P. (1998): Teorías contemporáneas del desarrollo económico, Editorial Síntesis.

CAÑIGUERAL, A. (2014): Vivir mejor con menos: Descubre las ventajas de la nueva economía colaborativa, Barcelona: Conecta.

CANYELLES, J.M. (2011): "Responsabilidad social de las administraciones públicas", Revista de Contabilidad y Dirección, 13(7).

CARPI, J.A. (2008): "El desarrollo local sostenible en clave estratégica", CIRIEC-España, Revista de Economía Pública, Social y Cooperativa, 61, 73-101.

COMITÉ ECONÓMICO Y SOCIAL EUROPEO (2016): "Dictamen del Comité Económico y Social Europeo sobre el tema La Economía del Bien Común: un modelo económico sostenible orientado a la cohesión social". En http://eur-lex.europa.eu/legalcontent/ES/TXT/?uri=uriserv:OJ.C_.2016.013.01.0026.01.SPA 
CORAGGIO, J.L. (1998): Economía popular urbana: una nueva perspectiva para el desarrollo local, Programa de Desarrollo Local, Instituto del Conurbano, UNGS, San Miguel.

CORTINA, A. (1993): Ética aplicada y democracia radical, Madrid, Tecnos.

DALY, H.E. \& COBB, J.R. (1989): For the common good. Redirecting the economy toward community, the environment and sustainable future, Boston, Beacon Press.

DÍAZ, I. (2006): "La transparencia informativa y ética social", Técnica económica: administración y dirección de empresas, 175, 19-21.

ESCOBAR, A. (2005): "El "postdesarrollo" como concepto y práctica social". En: D. Matto, coord. Políticas de economía, ambiente y sociedad en tiempos de globalización, Facultad Ciencias Económicas y Sociales, Universidad Central Venezuela, Caracas.

FELBER, C. (2012): La Economía del Bien Común, Grupo Planeta, Ediciones Deusto, Barcelona.

FREIRE, P. (1998): Pedagogy of freedom: Ethics, democracy, and civic courage. Rowman \& Littlefield.

FRIZZO, K.R. (2008): "La investigación-acción participante". En: E. Saforcda y J. Castellá, Enfoques conceptuales y técnicos en Psicología Comunitaria, Buenos Aires: Paidós.

GARRIGA, E. \& MELÉ, D. (2004): "Corporate social responsibility theories: Mapping the territory", Journal of Business Ethics, 53(1), 51-71.

GARCÍA CALVENTE, Y. (2015): "Economía del bien común. Análisis y propuestas sobre la constitucionalidad de su incentivación fiscal", CIRIEC-España, Revista Jurídica de Economía Social y Cooperativa, 26, 261-301.

GÓMEZ, V. \& GÓMEZ-ÁLVAREZ, R. (2016): "La Economía del Bien Común y la Economía Social y Solidaria, ¿son teorías complementarias?", CIRIEC-España, Revista de Economía Pública, Social y Cooperativa, 87, 1-38.

GUDYNAS, E. (2014): "El postdesarrollo como crítica y el Buen Vivir como alternativa". En: Delgado Ramos (coord.), Buena Vida, Buen Vivir: imaginarios alternativos para el bien común de la humanidad, Colección Debate y Reflexión, Universidad Nacional Autónoma de México, 61-95.

HAWORTH, J. \& GRAHAM, H. (Eds.) (2007): Well-being, individual, community and social perspectives, Basingstoke: Palgrave Macmillan.

HAYEK, F.A. (1986): Camino de servidumbre, Universidad Autónoma de Centro América.

HERRERO, Y. (2012): "Propuestas eco-feministas para un sistema cargado de deudas", Revista de Economía Crítica, 13, 30-54.

HIDALGO-CAPITÁN, A.L. (2011): "Economía política del desarrollo: la construcción retrospectiva de una realidad académica", Revista de Economía Mundial, 28, 279-320.

HIRSCHMAN, A. (1980): "Auge y ocaso de la teoría económica del desarrollo", El Trimestre Económico, 188: 1055-77. 
JURADO GILABERT, F. (2013): "Democracia 4.0: desrepresentación en el voto telemático de las leyes", Revista Internacional de Pensamiento Político, 8, 119-138.

KANT, I. (1989): Fundamentación de la metafísica de las costumbres, ed. Adela Cortina, Tecnos, Madrid.

LATOUCHE, S. (2007): Sobrevivir al desarrollo. De la descolonización del imaginario económico a la construcción de una sociedad alternativa, Barcelona: Icaria Editorial.

MELLE HERNÁNDEZ, M. (2014): "La responsabilidad social en el sector público", Revista de Responsabilidad Social de la Empresa, 18, 17-43.

MINHAFP (2013): La responsabilidad social en la administración general del Estado. Memoria-informe sobre las prácticas socialmente responsable. 2012. En: http://www.sefp.minhafp.gob.es/dam/es/web/areas/funcion_publica/responsabilidadsocial/MEMORIA_RS-2012.pdf.

NACIONES UNIDAS (2006): Social Justice in an Open World: The Role of the United Nations, New York.

NORTH, D.C. (1990): Institutions, Institutional Change and Economic Performance, Cambridge: Cambridge University Press.

NOZICK, R. (1974): Anarchy, State and Utopia, NY: Basic.

NUSSBAUM, M. (2000): Women and Human Development, Cambridge University Press, Cambridge.

OSTROM, E. (2013): Comprender la diversidad institucional, KRK, Oviedo.

OTEO, O.V. (2005): "La responsabilidad social corporativa: el papel de la sociedad civil", CIRIECEspaña, Revista de Economía Pública, Social y Cooperativa, 53, 111-124.

PARÉS, M. (Ed.) (2009): Participación y calidad democrática: evaluando las nuevas formas de democracia participativa, Ariel, Barcelona.

PIERRE, J. \& PETERS, G.B. (2000): Governance, politics and the state, St. Martin's Press, New York.

POLANYI, K. (2001): The Great Transformation: The Political and Economic Origins of Our Time, Beacon Press, Boston (1st edition, 1944)

RAHTZ, D.R., SIRGI, M.J. \& PHILLIPS, R. (Eds.) (2013): Community quality-of-life indicators: Best cases IV, Dordrecht: Springer.

RAPLEY, M. (2003): Quality of life research. Los Angeles: Sage.

RAZETO, L. (2015): Tópicos de Economía Comprensiva, Ediciones Univérsitas Nueva Civilización, Santiago de Chile.

RONDINELLA, T., SEGRE, E. \& ZOLA, D. (2015): "Participative Processes for Measuring Progress: Deliberation, Consultation and the Role of Civil Society", Social Indicators Research, doi:10.1007/s11205-015-1207-z 
SALVARIS, M. (2000): Community and social indicators: How citizens can measure progress, and overview of social and community indicator projects in Australia and Internationally. Hawthorn: Institute for Social Research, Swinburne University of Technology.

SANDEL, M.J. (2000): El liberalismo y los límites de la justicia, Gedisa.

SEN, A. (1999): Development as Freedom, Nueva York: Knopf

SINTOMER, Y. (2005): "Los presupuestos participativos en Europa: retos y desafíos", Revista del clad Reforma y Democracia, 31(1), 1-17.

STIGLITZ, J.E., SEN, A. \& FITOUSSI, J.P. (2013): Medir nuestras vidas, RBA Libros.

UNCETA, K. (2009): "Desarrollo, subdesarrollo, maldesarrollo y postdesarrollo. Una mirada transdisciplinar sobre el debate y sus implicaciones", Carta latinoamericana, 7, 1-34.

WCED (World Commission on Environment and Development) (1987): Our common future: Report of the World Commission on Environment and Development, Brussels.

ZAMAGNI, S. \& BRUNI, L. (2007): Economia civile: efficienza, equità, felicità pubblica, II Mulino, Bologna.

ZURBANO, M., BIDAURRATZAGA, E. \& MARTÍNEZ, E. (2014): "Las transformaciones de los modelos territoriales de desarrollo en el contexto de la globalización. Aportaciones desde la perspectiva del desarrollo humano local", Revista de Estudios Regionales, 2014 (1), 103-133.

\section{Sitios web sobre municipios afines a la Economía del Bien Común}

ALBORAYA: http://www.elsalmoncontracorriente.es/?Alboraya-Del-blanc-al-blues

CARCABOSO: http://ayuntamientocarcaboso.blogspot.com.es/2014/07/economia-del-bien-comun.html

EIBAR: http://www.ebceuskadi.org/la-economia-del-bien-comun-aterriza-en-eibar/

LA CAROLINA: http://lacarolina.innovasur.es/

MIRANDA DE AZÁN: https://www.mirandadeazan.com/municipio-del-biencom\%C3\%BAn/presentacion/

MURO DE ALCOY: http://www.elsalmoncontracorriente.es/?Muro-de-Alcoy-La-utopia-cercana

ORENDAIN: http://www.orendain.eus/eu/

RIVAS-VACIAMADRID: http://www.elsalmoncontracorriente.es/?Rivas-Vaciamadrid-La-calle-llena

SANTA LUCÍA DE TIRAJANA: http://www.elsalmoncontracorriente.es/?Santa-Lucia-de-Tirajana-Otro SEVILLA: https://ebcsevilla.wordpress.com/2016/09/17/convenio-ebc-ayto-sevilla/ 